\title{
AVALIAÇÃO DA APRENDIZAGEM: UM OUTRO ENFOQUE
}

\author{
Alcir Horácio da Silva*
}

\section{ReSUMO}

O presente artigo tem como objeto de reflexão a avaliação da aprendizagem. Nosso objetivo é dar um novo enfoque para esta categoria a partir das inter-relações da avaliação com diferentes categorias que interagem diretamente com ela, como é o caso do projeto histórico, do projeto político-pedagógico e da organização do trabalho pedagógico, entre outras. Nossa proposta é mostrar que na escola, no atual modelo histórico, não há relação da categoria avaliação com outras categorias importantes para compreendê-la numa dimensão mais ampla. Além disto, a avaliação é tratada de forma meramente técnica, sem considerar os aspectos sócio-políticos que determinam sua utilização na escola. Por tudo isto, a escola a utiliza como instrumento perverso de estratificação social, reproduzindo o sistema dominante no qual, em sua base piramidal, estão os alunos oriundos da classe trabalhadora que ficam reprovados e acabam excluídos ou eliminados da escola.

PALAVRAS-CHAVE: avaliação, projeto político-pedagógico, escola.

\section{Learning evaluation: another focus}

\section{ABSTRACT}

This paper has as object of reflection the evaluation of learning. Our goal is to give a new focus on this category from the inter-relations of evaluation to other important categories that interact directly with it, such as: the historic project, the political-pedagogic project and the organization of pedagogic work, among others. Our purpose is to show that in school, in the current historic model, there is no relation of the evaluation category with other important categories to understand the first one in an ampler dimension. Besides, evaluation is treated in a technical way, without considering the socio-political aspects that determine its utilization in school. For all that has been said, the school utilizes the evaluation as a perverse instrument of social stratification, reproducing the dominant system in which in its pyramidal base there are students from worker class that fail and they are excluded of school.

KEY WORDS: evaluation, political-pedagogic project, school.

* Mestre em Educação pela Faculdade de Educação da Universidade de Brasília e professor de Educação Física do Centro de Ensino e Pesquisa Aplicada à Educação da UFG. E-mail: al.cir@terra.com.br 


\section{INTRODUÇÃO}

A Organização Jaime Câmara promoveu um debate sobre o tema Avaliação, com o seguinte questionamento: a forma de avaliação escolar deve mudar? Pela resposta positiva e unânime dos participantes deste debate, ficou claro que a avaliação escolar deve mudar. Mas por que, para quê, como e onde mudar? É a avaliação que deve mudar ou professores, alunos, enfim, a comunidade escolar que deve olhá-la por um novo enfoque?

A polêmica sobre a avaliação se inicia quando um procurador da justiça do Estado recorreu, por via judicial, da reprovação de seu filho numa determinada escola particular de Goiânia. A partir desse fato, houve uma campanha contra a reprovação, logo ganhando as páginas dos jornais, com entrevistas e debates na televisão. De positivo, esse fato trouxe à tona um problema antigo nas escolas brasileiras, que tem merecido a elaboração de vários estudos, artigos, dissertações e teses por todo o país.

A avaliação da aprendizagem escolar conduz educadores de todas as áreas do conhecimento à reflexão, ao estudo e ao aprofundamento, visando buscar novas formas de entendimento e compreensão, acerca de seus significados no contexto escolar.

A literatura pertinente ao assunto é vasta e demonstra claramente a necessidade de compreender esta categoria de forma mais abrangente, evitando reduzi-la à uma dimensão mais técnica. Torna-se necessário examiná-la no contexto do projeto político-pedagógico que reflete o projeto histórico da sociedade.

A ausência dessa compreensão mais abrangente tem levado muitos educadores a enfrentar dificuldades, atribuindo-as a lacunas na formação inicial, quando deveriam receber conhecimentos sobre a avaliação da aprendizagem.

Entretanto, toda a produção teórica relacionada ao tema não consegue solucionar este complexo problema porque, a meu ver, a categoria avaliação é analisada sem nenhuma inter-relação com outras categorias importantes do processo pedagógico. Em outras palavras, a análise da categoria avaliação se pauta em discuti-la de forma fragmentada, meramente técnica, burocrática, sem considerar aspectos sócio-políticos (e por que não econômicos) que a envolvem na sociedade, o que, portanto, reflete o profundo desconhecimento da categoria avaliação como importante elemento básico, mas não único, da didática. 


\section{Aprofundando O TEMA}

Gostaria, então, de contribuir, com alguns elementos, para o aprofundamento do tema. Vários estudos têm sido produzidos sobre avaliação da aprendizagem. Entretanto, poucos são os trabalhos que a relacionam com o projeto histórico, ou seja, a sociedade que temos e a que queremos construir, que naturalmente se efetiva no projeto político-pedagógico. Explícito ou não (na maioria das instituições escolares ele está na cabeça de seus dirigentes e de seus professores), este projeto se materializa na organização do trabalho pedagógico, quer seja na organização da escola como um todo ou na dinâmica da sala de aula.

É importante destacar que a educação está inserida num contexto social e analisar a relação educação/sociedade é fundamental para entender a escola numa sociedade capitalista, pois, o papel desempenhado por ela passa pela reprodução do modo de produção da sociedade.

Freitas (1991) destaca que a escola não é uma ilha na sociedade. A escola, portanto, não está totalmente determinada pela organização social, mas também, não está totalmente livre de suas influências. Entender, segundo ele, estas limitações, para a organização do trabalho pedagógico é imperioso para lutarmos contra elas. Desconsiderá-las, conduz à ingenuidade e ao romantismo.

A produção da vida material do homem advém do trabalho. É através dele que se relaciona com a natureza, transformando-a, adequando-a à sua sobrevivência e produzindo seus conhecimentos. $\mathrm{O}$ trabalho assume, portanto, várias particularidades, segundo a maneira pela qual o homem organiza o modo de produção de sua vida material. Ainda segundo Freitas (1991), no presente momento histórico, o trabalho é caracterizado pelo trabalho assalariado. O homem (empregado) vende sua força de trabalho, por uma determinada quantia de dinheiro a outro homem (patrão), que possui os meios de produção, ou seja, o capital. As relações entre o trabalho e o capital se apresentam antagônicas, uma vez que é a partir do trabalho que o capital se valoriza cada vez mais, mediante a exploração da força do trabalhador. A conseqüência desse antagonismo faz os homens não serem iguais, nesse tipo de sociedade.

Por outro lado, a divisão do trabalho manual e do trabalho intelectual determina a apropriação do conhecimento, condenando grande massa de operários à ignorância e a trabalhos mecânicos parcelarizados, valorizando, assim, o capital. 
Percebe-se, portanto, que o modelo liberal, adotado por nossa sociedade, mostra algumas contradições, pois nele, cada indivíduo pode e deve, mediante seu próprio esforço, livremente buscar sua auto-realização. Uma das características desse modelo é o individualismo, portanto, a ação individual garante o sucesso da pessoa. Conclui-se que todas as pessoas, neste modelo, são iguais e têm as mesmas oportunidades, o que não é verdade numa sociedade marcada pelas contradições sociais. É fundamental, portanto, abrirem-se discussões críticas sobre a escola no modelo liberal.

As transformações econômicas e políticas que estão ocorrendo no mundo atual denotam claramente a dificuldade que o modelo liberal tem em resolver as questões sociais de uma sociedade. Educação, saúde e emprego estão em colapso, principalmente na América Latina. Os altos níveis de desemprego no mundo acirram o individualismo e mesmo aqueles que possuem nível universitário ficam privados de trabalhar, por falta de oferta de emprego.

Nossa análise é a de que, na divisão do trabalho intelectual e do trabalho manual, até mesmo os que conseguem se destacar e chegar em uma universidade têm dificuldades para conseguir o emprego almejado. Neste sentido, fazemos a inferência de que aqueles que ficam na base da escala, em relação à escolaridade, irão fazer parte de outra categoria: a dos excluídos.

O fracasso escolar está evidenciado no alto número de reprovação, principalmente em séries iniciais, na eliminação/manutenção e por fim, na evasão escolar. Vários autores, entre eles Freitas (1995), Franco (1995) e Patto (1990), têm denunciado que a avaliação escolar tem servido para reproduzir o modelo dominante, pois, fica caracterizado claramente que aqueles que conseguiram êxito na escola estarão propensos a conseguirem êxito na vida. Situação inversa ocorre com a grande maioria, principalmente, com aqueles oriundos das escolas públicas e das classes trabalhadoras. É, portanto, mister o aprofundamento da avaliação, como foi dito, e também da prática pedagógica do professor na organização do trabalho pedagógico, principalmente em sala de aula, pois, os critérios e procedimentos adotados por ele podem determinar o destino do aluno, separando aqueles que farão parte do trabalho intelectual e do trabalho manual e, também, da categoria dos excluídos.

A escola capitalista tem forte vocação elitista, é uma escola de classe, portanto não é para todos. Somente o acesso não garante a permanência dos alunos nem a qualidade de ensino, bastante questionada ultimamente. Ela, então, incorpora funções sociais que adquire de acordo com o projeto de sociedade na qual está inserida e, para garantir que estas funções sociais sejam efetivadas, utiliza os procedimentos de avaliação. 
A educação tem, segundo Mészáros (1981, apud Freitas, 1995), duas funçōes principais numa escola capitalista: produção de qualificação para o mercado e elaboração de métodos para um controle político.

É fácil comprovar com dados oficiais que o sistema educacional brasileiro é piramidal e, para exemplificar, basta observarmos as estatísticas do Ministério da Educação (MEC/INEP, 2005) na relação existente entre alunos que entram na $1^{\text {a }}$ série do ensino fundamental e os que concluem o ensino superior. $\mathrm{O}$ índice de reprovação é tão grande nas primeiras séries do ensino fundamental e se afunila tanto nas demais séries, que se forma uma verdadeira pirâmide de exclusão social, em cuja base se localiza um grupo imenso de alunos, geralmente oriundos das classes menos favorecidas da sociedade, em contraste com o seu ápice, que mostra um pequeníssimo grupo, geralmente oriundo de classes mais privilegiadas. Nesse sentido, percebe-se claramente a utilização da categoria avaliação como instrumento perverso da ideologia dominante, pois a forma como ela é realizada nas escolas determina aqueles que farão parte da classe dominante e da classe dominada.

Autores como Bourdieu e Passeron (1975) nos chamam a atenção para um tipo de seleção - a manutenção e a eliminação adiada - que é aquela em que os alunos de classes sociais menos privilegiadas transitam orientados para determinadas profissōes, em geral menos valorizadas, enquanto outros se dirigem para níveis mais altos de escolaridade, em que as profissões sociais e econômicas são mais valorizadas, internalizando, assim, a divisão entre trabalho manual e trabalho intelectual.

Freitas (1995) afirma que é possível que a categoria mais decisiva para assegurar a função social que a escola tem na sociedade capitalista seja a avaliação. Entretanto, percebemos nos conselhos de classe, dos quais participamos em nossa escola, a preocupação excessiva que os professores têm em relacionar o conteúdo como principal elemento da avaliação, conquanto acreditamos e concordamos com Freitas (1995), que o principal elemento balizador para a avaliação é o objetivo. Embora em nenhum momento queiramos desprezar a importância do conteúdo, avaliar tendo-o como referência, é avaliar o produto.

Precisamos avaliar segundo nossos objetivos e considerar todo o processo de construção do conhecimento elaborado pelo aluno. É importante enfatizar que a escola tem uma função social e seu trabalho pedagógico está na dependência de seus objetivos. Nesse sentido, Freitas (1995, p. 
144) assegura que o par dialético avaliação/objetivos deve ser o modulador do outro par dialético, conteúdo/método, pois segundo ele, o primeiro par dialético é "a chave para compreender e transformar a escola, nos limites do atual momento histórico".

O Brasil, país em desenvolvimento, precisa investir nas políticas sociais, principalmente na educação. Para a adoção desta política, busca-se a parceria de organismos internacionais como o Banco Mundial, a Unesco, entre outros. Essa parceria, no entanto, custa para a população brasileira um alto preço, pois ficamos subservientes aos ditames desses organismos e acabamos reproduzindo um projeto histórico de sociedade (neoliberal), cujas características principais são a individualidade, a violência, a corrupção, a imoralidade, a miséria, a desumanidade, a injustiça, entre outras. Características estas que queremos transformar e acreditamos, utopicamente, que podemos fazê-lo por meio da escola.

Mas qual sociedade? A que temos ou a que queremos? Para nos ajudar a responder estas perguntas, Freitas $(1987$, p.122) se refere à categoria Projeto Histórico como "um projeto que enuncia o tipo de sociedade ou organização social na qual pretendemos transformar a atual sociedade e os meios que deverão ser colocados em prática para a sua consecução". No quadro a seguir, exemplificamos as características da sociedade atual e as da que se pretende. Indubitavelmente, a escola pode contribuir para o trajeto em direção à sociedade que se almeja. Entretanto, ela é fortemente afetada pela organização social na qual vivemos e, por isso, reproduz os valores destacados na primeira coluna do quadro abaixo.

QUADRO 1 - Características das sociedades atual e que se pretende

\begin{tabular}{|l|l|}
\hline SOCIEDADE ATUAL & SOCIEDADE QUE SE PRETENDE \\
\hline Individualista & Coletiva \\
\hline Violenta & Sem Violência \\
\hline Desumana & Mais Humana \\
\hline Miserável & Melhores Condições de Sobrevivência \\
\hline Valores Deturpados & Valores Preservados \\
\hline Corrupta & Honesta \\
\hline Injusta & Justa \\
\hline Imoral & Ética \\
\hline
\end{tabular}

Fonte: $\mathrm{O}$ autor. 
Portanto, a escola, no atual modelo histórico, reproduz os valores destacados à esquerda e a avaliação da aprendizagem é utilizada, pela elite dominante, de forma perversa, como instrumento de manutenção desse status quo. E o mais grave disso é que, conscientemente ou não, a maioria de nós, educadores, reforça esta situação, por desconhecer os mecanismos sutis empregados pelo sistema dominante na utilização da avaliação para manutenção, classificação e exclusão dos alunos, principalmente os oriundos da classe trabalhadora.

Alguns estudiosos, entre eles Luckesi (1995) e Franco (1995) denunciam os alarmantes índices de evasão e repetência na educação básica nas escolas públicas. Para Franco (1995, p. 13), "as denúncias descritivas e, principalmente, quantificadas são importantes e necessárias por fornecerem indicadores e parâmetros que nos permitam perceber os desníveis e desequilíbrios do sistema educacional brasileiro". E conclui:

Assim, quando sabemos que $50 \%$ das crianças da escola pública repetem a $1^{a}$ série do Ensino Fundamental, enquanto essa percentagem, entre aquelas que freqüentam a rede de ensino privada não chega a 5\%, estamos comparando, avaliando e nos conscientizando acerca da magnitude e complexidade do problema (Franco, 1995, p. 13).

Os autores citados no parágrafo anterior indicam ainda que critérios subjetivos utilizados, principalmente na avaliação informal, ferem a autoestima dos alunos, classificando-os como "incapazes", "dementes", "burros", tudo isso acrescentado ao flagrante autoritarismo revelado nas ameaças diárias de nossa sala de aula, retratado em falas como: "quietinhos... sentadinhos... preste atenção... senão você vai ver o que vai te acontecer no dia da prova". Isto sem contar as provas mal formuladas nas quais a resposta tem que ser aquela que o professor espera, o teste "relâmpago", as várias "pegadinhas", enfim, a falta de critérios explícitos nas práticas avaliativas das disciplinas.

O Governo Federal, por meio do Ministério da Educação (MEC), adota políticas educacionais formuladas pelos organismos multilaterais, principalmente o Banco Mundial, que reforça esta situação. O maior exemplo está nos instrumentos utilizados para "avaliarem" a Educação Básica (Sistema de Avaliação da Educação Básica -SAEB), o Ensino Médio (Exame Nacional do Ensino Médio - ENEM) e o Ensino Superior (Sistema Nacional de Avaliação da Educação Superior - SINAES), instrumentos de avaliação que, entre outros objetivos, têm servido para o ranqueamento das instituições e para for- 
necer dados estatísticos, indicadores da melhoria (?) na qualidade de ensino, com o objetivo de continuar recebendo verbas dos organismos multilaterais.

Um paradoxo está presente nesta avaliação: na Educação Básica, as instituições privadas aparecem melhores classificadas, enquanto no ensino superior, mesmo com todo o sucateamento, desmantelamento e sem investimentos necessários ao seu pleno funcionamento, as públicas são as melhores. Esse fato, talvez explique, porque o MEC investiu na Educação Básica nos últimos anos e promoveu o sucateamento e o desmantelamento do Ensino Superior público, dito anteriormente.

Portanto, o interesse em privatizar as universidades públicas, responsáveis por grande parte das pesquisas produzidas no país, faz parte de um projeto maior que é a submissão aos interesses do capital internacional. Assim, a avaliação é utilizada como mecanismo de manter a ordem do projeto histórico que os organismos internacionais elaboraram para o Brasil e para toda a América Latina, na política educacional.

Outro elemento de reflexão é a utilização dos conceitos de avaliação e verificação como sinônimos. Etimologicamente, as palavras se originam do latim, mas têm significados diferentes. Avaliar, a-valere, quer dizer "dar valor a..." e implica numa tomada de decisão, positiva ou negativa, em relação ao sujeito/objeto avaliado. Portanto, ela não se encerra no valor ou qualidade atribuídos a um objeto ou a outrem. E mais, é dinâmica e não se encerra em si mesma. É diagnóstica, processual, sintética, formativa, o que indica que há necessidade de tomar uma decisão: manutenção ou modificação daquele ou daquilo que está sendo avaliado.

Diferentemente, a verificação, verum facere, que significa "fazer verdadeiro" é um processo que se configura na observação, obtenção, análise e síntese dos dados com a finalidade de comprovar algo ou uma verdade sobre um objeto, ato ou alguém, se encerrando no momento em que se chega à conclusão de que tal objeto, ato ou alguém possui determinada configuração ou conceito preestabelecido. A verificação, portanto, é estática e não permite que a partir dela se retire conclusões novas e significativas.

Segundo Luckesi (1995), a escola brasileira opera com a verificação porque os resultados da aprendizagem, usualmente, têm tido a função de estabelecer uma classificação do aluno, que se expressa na reprovação ou aprovação. Daí, o grande número de reprovação nas escolas, principalmente públicas, como dissemos anteriormente.

Portanto, o processo de aferição do conhecimento do aluno, se conduzido pela verificação, não traz conseqüências significativas para a melho- 
ria da qualidade de ensino, nem a melhoria da qualidade da aprendizagem, mas impõe conseqüências negativas pela constante ameaça da reprovação. Isto explica o nosso pavor quando vamos realizar qualquer processo seletivo por meio de provas.

Ao contrário, se o processo for conduzido pela avaliação, tem-se a oportunidade de diagnosticar a real condição em que está a aprendizagem, possibilitando ocorrer um (re)encaminhamento da ação, visando à consecução dos objetivos que se deseja alcançar, o que é possibilitado por este processo dinâmico.

Para o entendimento dessa diferenciação, Luckesi (1995) nos coloca um exemplo bastante esclarecedor: um paciente com dores no peito, na altura do pulmão, procura um médico. $\mathrm{O}$ médico o examina e identifica uma pneumonia em estado inicial. Avisa ao seu paciente que ele está com pneumonia e o manda para casa com retorno previsto para daí a 15 dias. $\mathrm{O}$ paciente, então, retorna com uma dor maior. $\mathrm{O}$ médico o reexamina e identifica que a pneumonia cresceu. Comunica ao seu paciente e o manda de volta para casa com retorno determinado para daí a mais 15 dias. É claro que o paciente não vai mais retornar ao hospital, porque ele vai morrer, uma vez que o que o médico fez foi somente verificar, tornar verdadeiro, aquilo que já estava identificado: a pneumonia. Entretanto, se ele de fato avaliasse o quadro clínico de seu paciente e, após o diagnóstico, utilizasse todos os meios para curar a pneumonia (repouso, remédios, boa alimentação, etc.), estaria de fato fazendo uma boa avaliação que o levaria a alcançar seu objetivo: curar o seu paciente. Não seria isto que estamos fazendo com nossos alunos? Identificando os vários problemas e reprovando-os, sem ao menos utilizarmos todos os recursos para aprová-los?

Parece-me que o caminho da verificação é o mais fácil. Avaliar dá muito trabalho...

O último elemento, por ora, que gostaríamos de considerar, é a relação da avaliação com a organização do trabalho pedagógico. Para Villas Boas (1993, p. 130),

a expressão trabalho pedagógico comporta dois significados. O primeiro se refere ao trabalho realizado pela instituição como um todo ou por um departamento. Nesse sentido, compõe o trabalho pedagógico, o conjunto de diretrizes da unidade que se refere nas atividades desenvolvidas por professores e alunos. O segundo, em sentido restrito, o trabalho pedagógico resulta da interação do professor com seus alunos, em sala convencional ou 
em outros espaços. Neste caso, é o trabalho realizado pelo professor com o grupo de alunos incluindo as tarefas docentes e discentes.

Portanto, é essa categoria que vai conferir um maior peso ao processo avaliativo porque todos os equívocos do processo pedagógico e das práticas avaliativas ocorrem nela.

Neste sentido, devemos transformar a "cela" de aula em uma verdadeira sala de aula, alegre, dinâmica, produtiva, prazerosa, locus do verdadeiro espaço pedagógico, onde professores e alunos aprendam e ensinem mutuamente para transformar esta sociedade que está aí, numa sociedade mais livre, participativa, autônoma e humana.

De acordo com Fusari (1990), a avaliação é apenas a ponta do "iceberg” do processo pedagógico e, se há problemas na avaliação, são apenas reflexos de problemas que ocorrem no processo pedagógico como um todo, na formulação dos objetivos, dos conteúdos e de sua metodologia. Segundo esse autor, há um ecletismo na avaliação escolar oriundo de uma série de teorias presentes na educação brasileira influenciando diretamente a formação dos professores que trabalham na educação básica.

Concordando com o autor, detenho-me num dos aspectos da organização do trabalho pedagógico, em sentido restrito, que é a relação do professor com os alunos em sala de aula. Vários pesquisadores em seus estudos, como por exemplo, Luckesi (1995), Hoffmann (1995), Villas Boas (1993), Freitas (1995) e Patto (1990), denunciam o autoritarismo na relação professor-aluno, no dia-a-dia da sala de aula. Em seus estudos, os autores mostram que muitos professores transformam suas aulas em verdadeiros espaços de terror, ameaçando e coagindo constantemente os alunos, para que eles obedeçam a determinado padrão de comportamento.

O que se percebe são as diversas formas de violência simbólica, traduzidas em palavras que diminuem a auto-estima dos alunos e tornam a aula, que deveria ser um momento de prazer, num momento de frustração.

Para exemplificar alguns momentos da organização do trabalho pedagógico que mostram o autoritarismo do professor, basta verificarmos que poucos professores explicitam e discutem com seus alunos, os seus planos de ensino e, principalmente, seus critérios de avaliação, enfim, sua prática avaliativa.

É fácil observar que, na maioria dos planos de ensino, os critérios para avaliação, não estão claros, o que indica que os alunos continuam sendo avaliados, e com um peso bastante considerável, de maneira informal, subjetiva e sem critérios. É comum alguns professores serem reconhecidos 
como bons professores porque o índice de reprovação em sua disciplina é alto. Alguns, inclusive, anunciam qual será o índice de reprovação da turma no primeiro dia de aula. Esta é uma maneira perversa de coação que alimenta o medo pela ameaça da reprovação.

Muitos professores continuam avaliando seus alunos da mesma forma como foram avaliados nos seus cursos de formação, o que indica falta de leitura e referencial teórico sobre a avaliação.

\section{À GUISA DE ALGUMAS SUGESTŌES...}

Portanto, sugiro que nós, professores de todos os níveis de ensino, aprofundemos os nossos conhecimentos sobre a categoria avaliação e as outras categorias que com ela se relacionam. Sugiro, ainda, que mudemos a nossa postura autoritária para uma postura democrática que permita aos alunos construírem sua autonomia.

Precisamos permitir a liberdade de expressão, com responsabilidade dos alunos, e trabalhar, conforme nos indica Pistrak (1981), a sua autoorganização, para que eles sejam co-responsáveis do processo pedagógico para a construção de uma nova escola, com a participação ativa da comunidade e, conseqüentemente, de uma nova sociedade. A auto-organização dos alunos tem o objetivo de permitir que participem da condução da sala, da escola e da sociedade, vivenciando desde o interior da escola, formas democráticas de trabalho que marcarão profundamente suas vidas e sua formação.

Penso que devemos investir (onde já tem) e incentivar a criação (onde não tem) dos Grêmios Estudantis para que estes sejam verdadeiros porta-vozes dos alunos na sua formação política, no conceito compreendido por Bertolt Brecht, teatrólogo alemão, autor de belíssimo poema que diz que o pior analfabeto é o analfabeto político.

É urgente que analisemos como estão os Conselhos de Classes nas escolas, pois sabemos que eles estão entre as práticas escolares que camuflam os mecanismos de controle, exclusão social e de poder, vigentes na sociedade. O Conselho de Classe é o momento e o espaço de uma avaliação diagnóstica da ação pedagógica e educativa feita por professores e alunos, à luz do projeto pedagógico da escola e é parte do processo de avaliação desenvolvido por ela. Podemos dizer que a forma como ele se organiza determina a forma como ocorre a avaliação escolar e vice-versa. Como estão esses Conselhos? Há participação efetiva dos alunos, representantes de suas 
turmas? Há um trabalho da escola para fazer valer a avaliação diagnóstica da ação pedagógica e educativa?

\section{FinALIZANDO...}

Não devemos imputar culpas aos professores, aos alunos, nem à família, pelo fracasso escolar. Todos nós somos responsáveis, direta ou indiretamente, por esse contexto. Devemos compreender a escola inserida no modelo capitalista, no atual momento histórico, e buscarmos formas de resistir a todos os interesses do capital em transformar a educação (um bem público) em uma mercadoria, em um comércio, enfim, em um bem comercial.

As políticas, para os vários níveis de ensino, devem estar voltadas para atender às várias contradições da nossa sociedade: analfabetismo, desemprego, fome, miséria, entre outras. Mister é exigir que o Ministério Público Federal fiscalize a destinação do percentual de investimentos previsto na Constituição Federal para a educação ( $25 \%$ estados, municípios e Distrito Federal). Esse percentual, além de não ser cumprido, é diminuído por meio de vários mecanismos de utilização de receitas, como é o caso da DRU (Desregulamentação das Receitas da União), que hoje utiliza 20\% das receitas da Educação e Saúde para outros fins.

É responsabilidade nossa, cobrar dos governantes uma política séria de valorização do professor e de todos os profissionais que labutam na educação, principalmente no que diz respeito a salários, a formação continuada, a melhores condições de trabalho e a ampliação de direitos sociais conquistados por aqueles que, com profissionalismo e amor, dedicam suas vidas para a educação... "dos filhos, desta Pátria Mãe Gentil. Pátria amada, Brasil".

\section{REFERÊNCIAS}

BOURDIEU, P.; PASSERON, J. C. A reprodução: elementos para uma teoria dos sistemas de ensino. Rio de Janeiro: Francisco Alves, 1975.

FRANCO, M. L. P. B. Pressupostos epistemológicos da avaliação educacional. In: SOUZA, C. P. S. (Org.). Avaliação do rendimento escolar. Campinas: Papirus, 1995.

FREITAS, L. C. de. Projeto histórico: ciência pedagógica e "didática". Educação e Sociedade, São Paulo, n. 27, p. 122-140, 1987. 
. Organização do trabalho pedagógico. SEMINÁRIO INTERNACIONAL DE ALFABETIZAÇÃO E EDUCAÇÃO, 7., Novo Hamburgo, RS. 1991. (Mimeo).

. Crítica da organização do trabalho pedagógico e da didática. Campinas: Papirus, 1995.

FUSARI, J. C. O planejamento e o ensino da avaliação. São Paulo: FTD, 1990. (Caderno Série Idéias).

HOFFMANN, J. Avaliação mediadora: uma prática em construção da préescola à universidade. Porto Alegre: Mediação, 1995.

LUCKESI, C. C. Avaliação da aprendizagem escolar. São Paulo: Cortez, 1995.

PATTO, M. H. A produção do fracasso escolar. São Paulo: T. A. Queiroz, 1990.

PISTRAK, M. M. Fundamentos da escola do trabalho. São Paulo: Brasiliense, 1981.

MEC/INEP. Avaliaçôes e censo educacional. Disponível em: <http//:Www. mec.gov.bp. Acesso em: 20 abr. 2005.

VILLAS BOAS, B. M. de F. As práticas avaliativas e a organização do trabalho pedagógico. 1993. 420 f. Tese (Doutorado em Educação) - Faculdade de Educação da Universidade Estadual de Campinas, Campinas, 1993.

Recebido em: 7 ago. 2005 Aceito em: 18 abr. 2006 